\title{
Working
}

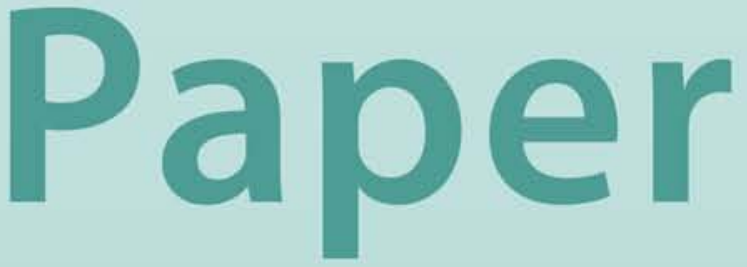


Financial Sustainability and Reform Options for the Albanian Pension Fund

\author{
Volker Treichel
}




\title{
IMF Working Paper
}

European I Department

\section{Financial Sustainability and Reform Options for the Albanian Pension Fund}

\author{
Prepared by Volker Treichel ${ }^{1}$
}

Authorized for distribution by Juha Kähkönen

April 2001

\begin{abstract}
The views expressed in this Working Paper are those of the author(s) and do not necessarily represent those of the IMF or IMF policy. Working Papers describe research in progress by the author(s) and are published to elicit comments and to further debate.
\end{abstract}

This paper studies the financial sustainability of the Albanian pension fund and assesses possible options for its reform. The paper concludes that the pension fund is not sustainable in its current form and proposes for the urban scheme a combination of parametric changes to the existing pay-as-you-go system that would be conducive to broadening the contribution base and strengthening the financial performance of the pension fund. In addition, it proposes the establishment of a voluntary funded pillar in the urban scheme. For the rural scheme, the paper concludes that it should either be merged with the scheme for the urban self-employed or be replaced by a mandatory and funded second pillar. The paper also proposes administrative reforms to strengthen revenue collections.

JEL Classification Numbers:E62, G23, H26

Keywords: Parametric reforms of pension funds, multi-pillar reforms, transition economies Author's E-Mail Address:Vtreichel@imf.org

' The author is grateful to Juha Kähkönen, Neven Mates, Hossein Samiei, Helga Treichel, and Ali Emini for helpful comments and suggestions. He would like to thank also Janet Bungay for editorial suggestions and Lina Shoobridge for secretarial assistance. 
Contents

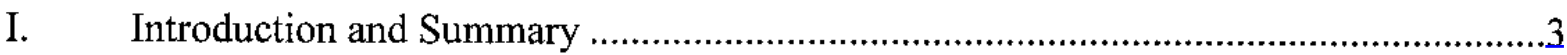

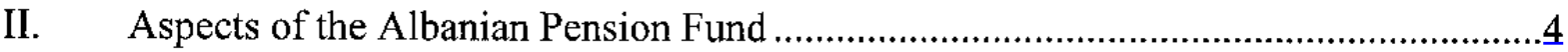

III. Financial sustainability and reform options for the Albanian Pension Fund...............10

A. Importance of Transition-Related Factors ........................................................11

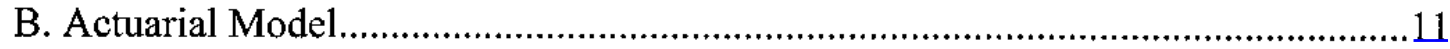

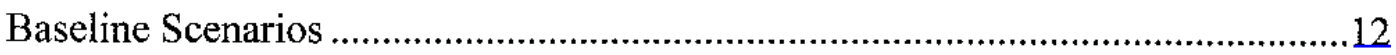

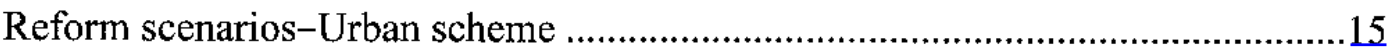

Reform scenarios-Rural scheme

C. Creation of Second and Third Pillars ............................................................21

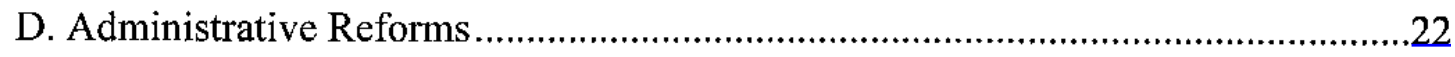

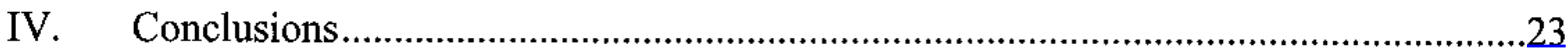

Text Tables

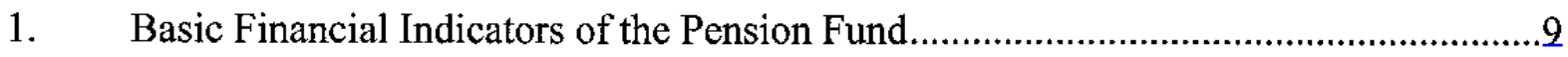

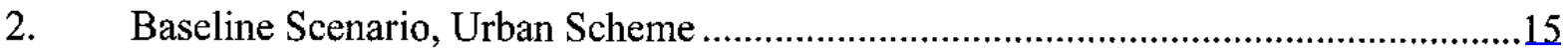

3. Policy Scenario I: Increasing Contribution Ceiling ..............................................16

4. Policy Scenario II: Increasing Contribution Ceiling and Maximum Benefits ..............17

5. Policy Scenario III: Increasing Contribution Ceiling-Reducing Contribution Rates ..17

6. Policy Scenario IV: Increasing Contribution Ceiling-Reducing Contribution Rates and Raising the Retirement Age ...........................................................................18

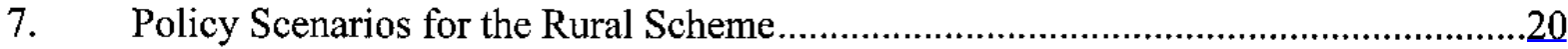

Text Boxes

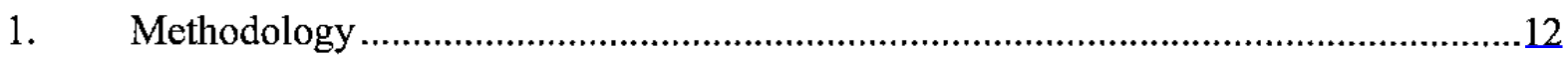

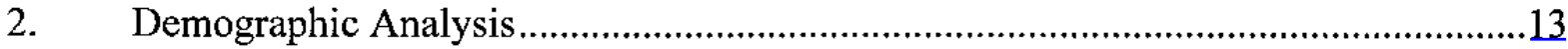

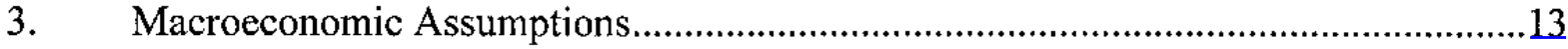

Figure

1. Relationship of the Income per Capita and Coverage …............................................

Tables

1. Some Indicators for the Social Security Systems of Different Countries.......................5

2. The Albanian Social Insurance System-Basic Indicators …………….........................6

3. The Albanian Pension Fund-Baseline Scenario .....................................................14

Appendix

Non-pension Related Functions of the Social Insurance Institute ..........................................24

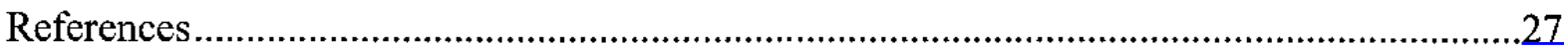




\section{INTRODUCTION AND SUMMARY}

Pensions are an important element of social protection in Albania. While over 15 percent of Albania's citizens currently receive pensions, private provision for retirement in the form of savings is limited. Traditional safety nets exist, in which the elderly are taken care of by their children, but the effectiveness and scope of these safety nets are decreasing as a result of social changes as well as internal and external migration that Albania has been experiencing since the beginning of the transition in 1991. The importance of the pension system as a cornerstone of social protection in Albania is expected to grow further, as the share of beneficiaries is projected to increase from its current level of 15 percent to about one-fourth of the population by the year 2050 . As the pension fund is relying at present on transfers from the budget in the amount of about 1 percent of GDP, its financial performance is of vital importance for the government's ability to increase expenditures on priority areas such as health, education, and infrastructure.

As in other transition economies, the social security system in Albania has been burdened by developments directly linked to the transition from a centrally planned to a market economy. These include a drop in reported employment resulting from the decline of the state sector and the rapid growth of an informal economy, as well as a surge of early retirement related to enterprise restructuring. In order to address these issues, pension systems in transition economies have been reformed through parametric changes of the pay-as-you-go system (PAYG) as well as the creation of second and third pillars, i.e., funded-defined contributions elements, participation in which could be either mandatory or voluntary.

Against this background this study looks at the financial sustainability of Albania's current PAYG system using an existing actuarial model that includes specific assumptions about key demographic and macroeconomic parameters. The main questions the study seeks to answer is whether or not the PAYG system is viable, whether it requires parametric reforms, and whether it may need to be supplemented with a second or third pillar. The study distinguishes between reform options for the urban and rural pension schemes, which differ considerably with regard to both the contribution rates and the benefits.

The paper concludes that the current parametric set up of the pension fund is not sustainable. The urban scheme, however, could be made sustainable by increasing the contribution ceiling and the retirement age combined with reducing contribution rates, under reasonable assumptions about improvements in the ratio of contributors to total work force (the coverage rate). To strengthen incentives for participation, an additional funded pillar within the urban scheme could be established in which participation would be voluntary, but contingent upon participation in the first pillar. For the rural scheme the paper concludes that it is not sustainable and should either be integrated with the urban self-employed scheme or-if this is not feasible-be replaced by a mandatory funded second pillar.

The first section of the paper describes the current functions and basic features of the pension fund. The second section discusses reform options and their financial impact both for the urban and the rural scheme using simulations based on an existing actuarial model, as well as 
options for the creation of a second and/or third pillar and administrative reforms. The third section concludes.

\section{Aspects of the Albanian Pension Fund}

The Albanian Social Insurance Institute (SSI), which was established in June 1992, currently fulfills three main functions: (i) the collection of social security contributions and payment of corresponding benefits, mostly old-age pensions; (ii) the administration of various social programs of the government, in particular price subsidies and special supplementary pensions for certain groups; and (iii) the collection of contributions to unemployment and health insurance. This paper focuses on the functions of the SSI as a pension fund, while the other functions are briefly described in the appendix.

While for the urban scheme contribution rates are high by international standards, for the rural scheme, contribution rates and the nominal income on which the rate is being applied are extremely low. The mandatory contribution rates for all employees in the urban scheme are 32.5 percent of the gross wage for the employer and 10 percent of the gross wage for the employee, with an additional 1.7 percent paid by both for health insurance. ${ }^{2}$ For the urban scheme, the ceiling for mandatory payments of contributions is defined in multiples of the minimum wage; currently the ratio is 1:3 and the ceiling Lek 23,319 (about US\$150) per month. Compared with other transition economies (Tables 1 and 2), Albania has among the highest contribution rates, with only Bulgaria and Kyrgyzstan at contribution rates of 39 percent and 36 percent, respectively, coming close. In the rural scheme, rates are 9 percent for mountainous regions and 15 percent for other rural areas, applied to a hypothetical annual income fixed in September 1993 at a level of Lek 10,800, currently about US $\$ 75$.

Although participation in the pension fund is mandatory, only about 37 percent of the work force contributed to the pension fund, with about 40 percent of the contributors coming from the state sector. ${ }^{3}$ Evasion of contributions is pervasive in particular in the private and the rural sectors, largely on account of high contribution rates and inefficiencies in the SSI's revenue administration, especially in the rural sector which has a long history of

\footnotetext{
${ }^{2}$ A contributor is entitled to the following benefits: old-age pensions, maternity, temporary incapacity and workmen's compensation.

${ }^{3}$ There is also a scheme of voluntary participation in the SSI created in 1994 for those individuals who were not obliged to participate in the system of social insurance, but nonetheless wished to insure themselves with the SSI. The vast majority of Albanians contributing to the voluntary scheme are illegal emigrants to neighboring countries who do not have the opportunity to contribute legally to schemes in their host countries. A key precondition for participation in the voluntary scheme is to have contributed previously for at least one month under the mandatory scheme.
} 
Albania: Table 1. Some Indicators for the Social Security Systems of Different Countries

\begin{tabular}{|c|c|c|c|c|c|c|c|c|c|c|c|c|c|c|c|}
\hline \multirow[t]{2}{*}{ Country } & \multirow{2}{*}{\multicolumn{3}{|c|}{$\begin{array}{l}\text { Contribution Rate 1/ } \\
\text { (in percent) }\end{array}$}} & \multirow[b]{2}{*}{$\begin{array}{c}\text { Self } \\
\text { employed }\end{array}$} & & \multicolumn{4}{|c|}{ Retirement Age } & \multicolumn{3}{|c|}{$\begin{array}{l}\text { Pension levels } \\
\text { (in US\$) }\end{array}$} & \multirow{2}{*}{\multicolumn{2}{|c|}{$\begin{array}{c}\text { Average public sector } \\
\text { wage } \\
\text { (in USS) }\end{array}$}} & \multirow[t]{2}{*}{$\begin{array}{l}\text { Replacement ratio } 2 / \\
\text { (in percent) }\end{array}$} \\
\hline & Total & & Employer & & & Men & Women & & $\begin{array}{l}\text { Years of } \\
\text { Contribution }\end{array}$ & & & Maximum & & & \\
\hline Álbania & 42.5 & 10 & 32.5 & 34.5 & & 60 & 55 & & 35 & & 3631 & 72 & & 120 & 30.0 \\
\hline Armenia & 31 & 3 & 28 & $12 ; 20$ & $4 /$ & $62 ; 57 ; 52$ & $57 ; 52 ; 47$ & & $25 ; 20 ; 15$ & 61 & 5.4 & 7.6 & & 158.5 & 3.4 \\
\hline Bulgaria 15/ & 32 & 6.4 & 25.6 & 32 & & 60.5 & 55.5 & & $37.5 ; 32.5$ & 61 & 21.7 & 75.4 & & 118 & 18.4 \\
\hline Croatia & 21.5 & 10.75 & 10.75 & 21.5 & & 60.5 & 55.5 & & 19.5 & & 177 & 560 & & 511 & 34.6 \\
\hline Czech Republic & 26 & 6.5 & 19.5 & $\ldots$ & & 60 & 55 & & 25 & & 70 & No maximum & & 321 & 21.8 \\
\hline Estonia & 20 & 0 & 20 & 33 & $7 \mid$ & 62.5 & 57.5 & & 15 & & 30 & No maximum & & 301 & 10.0 \\
\hline Kazakhstan & 31 & 1 & 30 & $\ldots$ & & 60.5 & 55.5 & & $25 ; 20$ & $6 /$ & 27.6 & 60 & & 229 & 12.1 \\
\hline Kyrgyzstan & 36 & 2 & 34 & $\ldots$ & & 60 & 55 & & $25 ; 20$ & 67 & 2.2 & 17.6 & & 23 & 9.5 \\
\hline Latvia & 32.58 & 9 & 23.58 & $\ldots$ & & 60 & 57 & & 10 & & 51 & No maximum & $9 /$ & 268 & 19.0 \\
\hline Lithuania & 24 & 1 & 23 & & & 62 & 60 & & 30 & & 19 & No maximum & & 283 & 6.7 \\
\hline Romania & $28 ; 33 ; 38$ & 5 & $23 ; 28 ; 33 \quad 10 /$ & $\ldots$ & & 60 & 55 & & $30 ; 25$ & $6 /$ & 24 & No maximum & $9 /$ & 125 & 19.2 \\
\hline Russia & 29 & 1 & 28 & 20.6 & & 60 & 55 & & $25 ; 20$ & $6 /$ & 5.2 & 15.6 & & 55 & 9.5 \\
\hline Poland & 19.52 & 9.76 & 9.76 & $\ldots$ & & 65 & 60 & & $25 ; 20$ & $6 /$ & 132 & 692 & & 389 & 33.9 \\
\hline Slovak Republic & 27.5 & 5.9 & 21.6 & 27.5 & & 60 & $53-57$ & $11 /$ & $25 ; 20$ & $6 /$ & 93 & 189 & & 148 & 62.8 \\
\hline Slovenia & 24.35 & 15.5 & 8.85 & $\ldots$ & & $65 ; 63 ; 58$ & $60 ; 58 ; 53$ & & $15 ; 20 ; 40$ & $12 /$ & see ft. 13/ & see ft. 14/ & & 153 & \\
\hline
\end{tabular}

Source: US Social Security Administration and IMF publications. Data refer to 1999, unless indicated otherwise.

1/ Contribution rates are the mandatory contribution rates to the social security systems, excluding health and unemploymeng insurance.

2/ Ratio of minimum pension to average public sector salary.

3/ In the urban scheme; in the rural scheme the minimum pension is US\$ 8 .

4/ The former for farmers; the latter for urban self-employed

5/ Depending on how hazardous the work is

6/ The first figure refers to the mandatory contribution period for men, the second to that for women.

$7 /$ Self-employed pay 33 percent of income equal to or above the minimum salary.

8/ Pensions equal the amount of insured's contributions plus annual capital growth which is adjusted according to changes in the earnings index .

9/ Maximum pension is 85 percent of reference wage, which is average base earnings of best five consecutive years during last 10 years.

10/ Depending on work conditions.

11/ Depending on the number of children raised.

12/ Retirement age depends on the contribution period

13/ Minimum is 35 percent (men) or 40 percent (women) of average earnings during 10 highest paid consecutive years in insured period from 1970.

14/ Maximum pension is 85 percent of base earnings set by insurance association.

$15 /$ The data refer to 2000 . In 2001, total and self-employed pension contribution rates were lowered by 3 percentage points, while keeping the ratio of contributions by employees and employers the same.

In addition, retirement age and years of contribution for both men and women were increased by 6 months. 
Albania: Table 2. The Albanian Social Insurance System - Basic Indicators

\begin{tabular}{|c|c|c|c|c|c|c|c|c|c|}
\hline & Unit & 1993 & 1994 & 1995 & 1996 & 1997 & 1998 & 1999 & 2000 \\
\hline \multicolumn{10}{|l|}{ I. DEMOGRAPHIC INDICATORS } \\
\hline Population & Physic no & $3,167,500$ & $3,202,000$ & $3,248,800$ & $3,283,000$ & $3,324,300$ & $3,354,300$ & $3,373,400$ & $3,445,013$ \\
\hline Labor Force & Physic no & $1,347,000$ & $1,423,000$ & $1,309,000$ & $1,274,000$ & $1,301,000$ & $1,320,000$ & $1,305,000$ & $1,342,696$ \\
\hline \multicolumn{10}{|l|}{ Age structure } \\
\hline Below 16 & Physic no & $1,067,394$ & $1,068,750$ & $1,070,698$ & $1,081,937$ & $1,095,078$ & $1,093,922$ & $1,092,713$ & $1,156,824$ \\
\hline Women above $60 /$ men above $651 /$ & Physic no & 336,682 & 347,199 & 358,587 & 362,391 & 367,717 & 372,278 & 368,957 & 382,336 \\
\hline \multicolumn{10}{|l|}{ II. CONTRIBUTIONS - BENEFITS } \\
\hline Contributors & Average no & 731,000 & 479,000 & 459,330 & 432,200 & 348,038 & 362,397 & 422,943 & 492,261 \\
\hline Urban & Average no & 691,000 & 436,618 & 415,449 & 399,637 & 321,315 & 323,860 & 309,049 & 312,770 \\
\hline Rural & Average no & 40,000 & 42,382 & 43,881 & 32,563 & 26,723 & 38,537 & 113,894 & 179,491 \\
\hline Number of beneficiaries & Physic no & 470,387 & 473,293 & 482,336 & 497,110 & 506,176 & 515,232 & 526,807 & 538,031 \\
\hline Urban & Physic no & 313,172 & 317,035 & 321,218 & 331,160 & 336,782 & 340,983 & 349,602 & 356,621 \\
\hline Old-age pensions & Physic no & 238,454 & 247,310 & 249,274 & 252,861 & 254,588 & 257,775 & 265,964 & 271,715 \\
\hline Other benefts & Physic no & 74,718 & 69,725 & 71,944 & 78,299 & 82,194 & 83,208 & 83,638 & 84,906 \\
\hline Rural & Physic no & 157,215 & 156,258 & 161,118 & 165,950 & 169,394 & 174,249 & 177,205 & 181,410 \\
\hline Old-age pensions & Physic no & 124,389 & 130,301 & 134,888 & 140,049 & 143,098 & 147,984 & 151,502 & 155,655 \\
\hline Other benefts & Physic no & 32,826 & 25,957 & 26,230 & 25,901 & 26,296 & 26,265 & 25,703 & 25,755 \\
\hline Average monthly pension (urban) & in Lek & 1,740 & 2,240 & 2,840 & 3,380 & 3,346 & 4,212 & 4,679 & 5,142 \\
\hline Average monthly pension (rural) & in Lek & 538 & 700 & 700 & 875 & 818 & 984 & 980 & 1,132 \\
\hline \multicolumn{10}{|l|}{ III.. ANALYTICAL INDICATORS } \\
\hline \multicolumn{10}{|l|}{ Average real pensions } \\
\hline Urban & in Lek & 2,299 & 2,414 & 2,840 & 2,999 & 2,229 & 2,326 & 2,574 & 2,787 \\
\hline Rural & in Lek & 711 & 754 & 700 & 776 & 545 & 543 & 539 & 614 \\
\hline \multicolumn{10}{|l|}{ Average replacement ratios $2 /$} \\
\hline Urban & $\%$ & 36.7 & 32.3 & 32.5 & 32.2 & 31.9 & 31.8 & 30.1 & 30.1 \\
\hline Rural & $\%$ & 11.4 & 10.1 & 8.0 & 8.3 & 7.8 & 7.4 & 6.3 & 6.6 \\
\hline Coverage rate (Contributors/work force) & $\%$ & 54.3 & 33.7 & 35.1 & 33.9 & 26.8 & 27.5 & 32,4 & 36.7 \\
\hline Benefit population/Population & $\%$ & 14.9 & 14.8 & 14.8 & 15.1 & 15.2 & 15.4 & 15.6 & 15.6 \\
\hline Total Dependency ratio 3/ & $\%$ & 1.6 & 1.0 & 1.0 & 0.9 & 0.7 & 0.7 & 0.8 & 0.9 \\
\hline Urban & $\%$ & 2.2 & 1.4 & 1.3 & 1.2 & 1.0 & 0.9 & 0.9 & 0.9 \\
\hline Rural & $\%$ & 0.3 & 0.3 & 0.3 & 0.2 & 0.2 & 0.2 & 0.6 & 1.0 \\
\hline \multicolumn{10}{|l|}{ IV. MEMORANDUM ITEMS: } \\
\hline Average public sector salary & in Lek & 4,738 & 6,942 & 8,745 & 10,491 & 10,491 & 13,234 & 15,527 & 17,080 \\
\hline Minimum wage & in Lek & 1,200 & 2,440 & 3,400 & 4,400 & 4,400 & 5,800 & 6,380 & 7,773 \\
\hline Budgetary transfers to the pension fund & & & & & & & & & \\
\hline on account of the rural scheme & in min Lek & 0 & 368 & 518 & 157 & 510 & 910 & 2,998 & 4,653 \\
\hline in percent of GDP & $\%$ & 0 & 0.20 & 0.23 & 0.06 & 0.15 & 0.20 & 0.59 & 0.87 \\
\hline GDP & in min Lek & 125,300 & 187,900 & 224,746 & 280,998 & 341,716 & 460,631 & 506,205 & 536,429 \\
\hline CPI & Index & 75.7 & 92.8 & 100.0 & 112.7 & 150.1 & 181.1 & 181.8 & 184.5 \\
\hline
\end{tabular}

Source : Albanian Social Insurance Institute and Statistical Office

1/ There are no data available for the population above working age, I.e. women above 55 and men above 60 years.

$2 /$ Average replacement ratios $=$ Average pension/average salary in the public sector

$3 /$ Dependency ratio $=$ No. of contributors/pensioners 
noncompliance. Evasion is reflected either in a failure to register or in noncompliance among registered individuals. The first phenomenon is typical of the private sector in urban areas, while the latter is common in rural areas: Currently, only some 80,000 employees-or an estimated 40 percent of all employees in private urban companies-are known to the SSI, of which about 80 percent pay contributions. In rural areas, on the contrary, most farmers are registered, but compliance is quite low, at about 36 percent. In spite of the obvious inefficiencies in enforcing compliance with the social security legislation, Albania's overall coverage rate is broadly in line with that of other countries at similar income levels (see Figure 1).

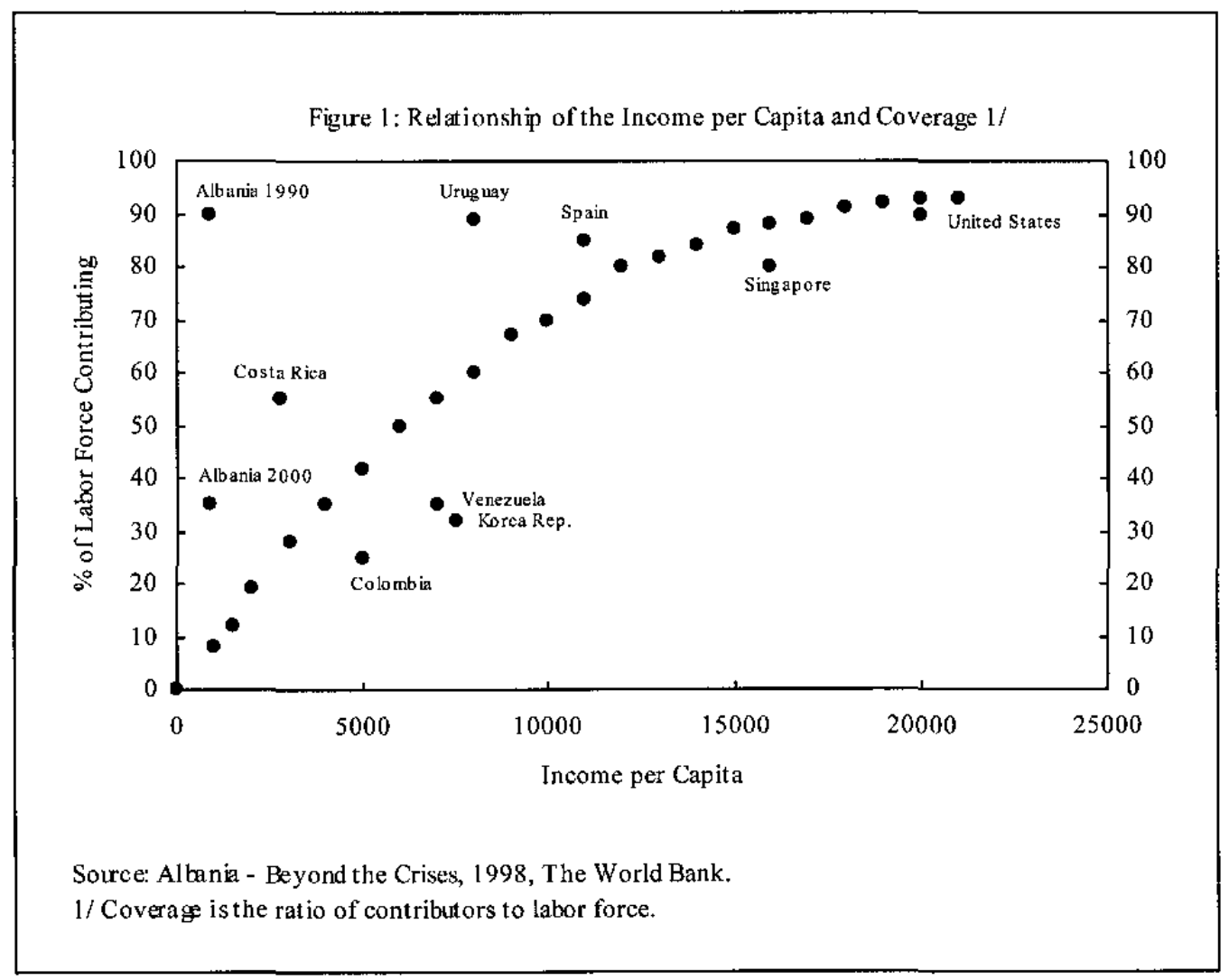

The dependency ratio-the ratio of contributors to beneficiaries-is very low in Albania. Demographic developments, a drop in reported employment, as well as the abandonment of a de facto full coverage for the rural scheme by the state budget in $1994^{4}$ led to a steady deterioration of the dependency ratio from 4.5 in 1990 to 1.6 in 1993 and further to 0.8 in 1999 . For the year 2000 , preliminary data show an improvement of the dependency ratio to 0.9 , following determined efforts by the government to increase the number of contributors, particularly in the rural sector. Pensions are paid after a minimum contribution

${ }^{4}$ In 1994, the Law obliged farmers for the first time to contribute to the pension system, albeit at a rate that heavily subsidized the pensions they were going to receive. Previously, the budget covered all contributions for farmers. 
period of 35 years, with the retirement age for women being 55 and for men, 60 years. ${ }^{5}$ The pension formula for the urban scheme adds to the base pension-currently Lek 5,142 (about US\$35) per month-a supplement that is calculated as 1 percentage point of the pension calculation base per year of insurance. The pension calculation base is the average of the indexed salaries earned by a contributor since $1994 .{ }^{6}$ Since many new pensioners have never contributed under the post-communist system, they are not entitled to a supplement. As a result, the average urban pension is close to the minimum urban pension. The maximum pension may not exceed 75 percent of the pension base and cannot be higher than twice the minimum pension.

These arrangements result in two types of distortions. On the one hand, for contributors in the lower to middle segment of the taxable wage range the replacement ratio is significantly more favorable than for those close to the contribution ceiling, since the maximum pension is considerably lower than the ceiling up to which social security contributions have to be paid. On the other hand, the contribution formula is rather regressive since wage earners below the contribution ceiling (i.e., those with lower and middle incomes) pay a proportionately higher part of their wages as contributions than those with salaries above the ceiling.

Rural pensions are paid at a basic rate of Lek 1,328 (currently) and in addition to this, a supplement that equals 1 percent of the monthly minimum wage for every year of contribution to the SSI since 1994. If the SSI contribution period falls short of the required 35 years, a farmer is entitled to the basic rural pension prorated by the number of years he has contributed. If the farmer has contributed for fewer than 20 years, the retiree is entitled only to social assistance benefits (ndihma ekonomike). ${ }^{7}$ While socially plausible-given the need to protect especially the destitute rural population in particular-the discrepancy between contributions and benefits in the rural scheme resulted in a substantial financial burden to the pension fund and the budget. In 1999, total contributions from the rural scheme amounted to some Lek $720 \mathrm{mn}$, as against expenditures of Lek $1.9 \mathrm{bn}$, or a deficit of 60 percent of expenditures (equivalent to about 0.2 percent of GDP). Although large, this deficit amounted to less than half the average of the deficit of the rural scheme during the years 1995-98.

\footnotetext{
${ }^{5}$ For workers in the second hardship category (mainly some teachers and doctors), the retirement age is 58 , respectively 53 years, but by 2004 the retirement age for this category of workers will be increased gradually to the general retirement age. Overall, the retirement age in Albania is in line with most other transition economies (see Table 1).

${ }^{6}$ The indexation of past salaries for the purpose of calculating the pension is based primarily on the inflation rate.

${ }^{7}$ The system of social assistance (ndihma ekonomike) is outside the scope of this study. Total expenditures on this item amounted to about 1.3 percent of GDP in recent years.
} 
Table 1. Basic Financial Indicators of the Pension Fund ${ }^{8}$

(In millions of Lek, unless otherwise indicated)

\begin{tabular}{lrrrrrrr}
\hline & 1993 & 1994 & 1995 & 1996 & 1997 & 1999 & 2000 \\
\hline & & & & & & & \\
Revenues & 2,607 & 5,795 & 7,804 & 10,524 & 10,290 & 15,096 & 16,186 \\
$\quad$ Urban & 2,571 & 5,718 & 7,723 & 10,454 & 10.236 & 14,376 & 15,469 \\
Rural & 36 & 77 & 81 & 70 & 54 & 720 & 717 \\
& & & & & & & \\
Expenditures & 7,302 & 9,598 & 11,095 & 13,901 & 14,642 & 20,015 & 22,637 \\
$\quad$ Urban & 6,402 & 8,476 & 9,894 & 12,424 & 13,141 & 18,127 & 20,465 \\
$\quad$ Rural & 900 & 1,122 & 1,201 & 1,477 & 1,501 & 1,888 & 2,172 \\
Deficit of the urban scheme & 3,831 & 2,758 & 2,171 & 1,970 & 2,905 & 3,751 & 4,996 \\
In percent of GDP & 3.1 & 1.5 & 1.0 & 0.7 & 0.9 & 0.7 & 0.9 \\
Deficit of the rural scheme & 864 & 1,045 & 1,120 & 1,407 & 1,447 & 1,168 & 1,455 \\
In percent of GDP & 0.7 & 0.6 & 0.5 & 0.5 & 0.4 & 0.2 & 0.3 \\
& & & & & & & \\
\hline
\end{tabular}

This improved financial performance of the rural scheme is partly due to the creation of a special incentive scheme for farmers to enroll in the pension fund that was adopted in January 1999. The new scheme established a supplement to the basic rural pension for every year of contribution after 1994 and temporarily abolished all penalties that had previously been required to compensate for years in which no contributions had been paid. ${ }^{9}$ The response to this scheme, which was aggressively marketed by the SSI, was very strong: From 1998 to 1999 , the number of contributors in the rural scheme rose from some 39,000 to 140,000 and contributions paid increased from Lek 92 to Lek 720 million.

Even though the financial indicators show that the deficit of the rural scheme is significant, the financial performance of the pension fund is dominated by the urban scheme, which accounts for 90 percent of expenditures and almost all revenues. The deficit of the urban scheme amounted to about 0.7-0.8 percent of GDP in recent years. In 1993, it had reached a peak of 3 percent of GDP, as the linkage between contributions and wages that was created with the 1994 Law on Social Insurance had not yet been established. Over 1994-96, it declined as the basic framework for collecting revenue was put in place. Since then, it has been broadly constant. Nonetheless, the continuous decline in the number of contributors from the state sector as a result of privatization and civil service retrenchment creates a tendency for the deficit of the urban scheme to rise, as the integration of the private sector

${ }^{8}$ Revenues exclude administrative costs, and contributions to unemployment and health insurance, but include contributions paid by the budget for soldiers, unemployed, and others.

${ }^{9}$ In 1994, a first attempt to strengthen incentives for participation in the rural scheme had been undertaken by offering farmers the possibility to obtain a full urban pension if they contributed for more than 17 years to the new pension fund. This attempt failed, as farmers could not envisage contributing for such a long time to the pension fund, and the penalties to compensate for previously missed contibuting years were prohibitive. 
into the social security system may not proceed at a pace required to compensate for this decline in revenue.

The declared objective of the Albanian pension fund is to provide benefits to retirees that safeguard at least the minimum subsistence level. While in the urban scheme this goal seems to have been reached ${ }^{10}$, the current level of pensions in the rural sector falls short of the minimum existence level. Also, in spite of the sharp increase of prices since the beginning of transition, average urban pensions have increased in real terms by some 30 percent since 1991, while average rural pensions have declined by about 60 percent in real terms over the same period.

While the replacement ratio-calculated as the ratio of average pension and the net average wage in the public sector-has improved for urban pensions from 25 percent to 30 percent since 1991 and is close to that in a number of transition economies ${ }^{11}$, it has declined for rural pensions from 18 percent to 7 percent and is probably extremely low, although conclusions are uncertain, owing to the absence of reliable wage data for the rural sector. In the past increases in pensions have been generally in line with increases in public sector wages to avoid deteriorations in the replacement ratio and address pensioners' concerns over the low purchasing power of their retirement benefits.

\section{Financial Sustainability and Reform Options for the Albanian Pension FUND}

A basic consideration affecting the analysis of the sustainability of the pension fund is the question whether or not transition-related, temporary factors have negatively impacted its financial soundness. If transitory factors have led to a deterioration of the pension fund's financial position, the granting of budgetary subsidies can be justified and the analysis within the actuarial model needs to explicitly factor in improvements in the financial situation of the pension fund that take place without the active intervention of policy makers. Before analyzing reform options to the PAYG-system for the urban and the rural scheme, this section therefore assesses the importance of transition-related factors for the financial situation of the pension fund.

\footnotetext{
${ }^{10}$ According to the World Bank (Albania: Growing out of Poverty, August 1996) the poverty line is some US $\$ 30$ per month.

${ }^{11}$ Table 1 calculates the ratio of minimum pension to average public sector wage, since data on average pensions are not available for all countries. For Albania, this ratio is, however, close to the ratio of average pensions to average wages, since average pensions are currently close to the minimum pension level.
} 


\section{A. Importance of Transition-Related Factors}

As in other transition economies, the financial soundness of Albania's pension fund has been adversely affected by the growth of the informal sector at a time when contributions from the state sector declined, owing to widespread bankruptcies and down-scaling of state-owned enterprises. In Albania, a steep decline in recorded employment occurred between 1990 and 1994 and resulted in a sharp drop in the number of contributors from almost 100 percent to one-third of the labor force. Since then the coverage rate has not improved markedly, which may be related both to weak administration of the collection system and to weak incentives to contribute, such as the high contribution rates adopted in 1993 and possibly the low replacement ratio. Those factors can hardly be considered transition-related problems, but rather reflect deeper structural shortcomings that will not disappear over time. They can therefore not justify the provision of temporary budgetary subsidies.

Another transition-related factor burdening the pension fund have been early retirement schemes. During 1991-93, state employees had the option of early retirement five years before regular retirement age at 75 percent of the ensured wage. Up to 1993, about 60,000 individuals took advantage of this scheme. Since in 1998 the last early retiree from this first wave of early retirees would have reached regular retirement age, these early retirees do not have an impact on the current financial situation of the SSI, even though they did increase the need for budgetary subsidies in intervening years. Since 1993, the use of early retirement schemes has been limited and resurfaced only in 1995 and 1996, when this option was offered to the mining sector. About 12,000 miners took advantage of these provisions which had only a marginal financial impact.

Overall, the importance of factors that have temporarily affected the financial viability of social security systems in other transition economies do not appear to justify the provision of budgetary subsidies in Albania. While weak administration is clearly still a factor, it needs to be addressed explicitly; moreover, the drop in registered employment and the limited participation of the labor force in the system may well be related to fundamental parameters of the system. The effects of early retirement on the system have, however, largely faded by now and do not materially affect the pension fund's current deficit

\section{B. Actuarial Model}

An actuarial model is used to determine the financial viability of the Albanian PAYG system and to study the need for parametric reforms-possibly supplemented with a funded second or third pillar. The model covers the period 2000-2048 and makes it possible to study the effect of different assumptions about participation and registration rates as well as parametric changes. ${ }^{12}$ Financial sustainability is defined as a gradual reduction in the need for budgetary

\footnotetext{
${ }^{12}$ The model is based on an actuarial model built for Albania by CALLUND. Manipulations were carried out by Mr. Ali Emini, Director of Financial Analysis at the Albanian Social Security Institute, and the author.
} 
transfers with the aim of phasing these transfers out completely. The methodology applied is briefly explained in Box 1. Underlying demographic and macroeconomic assumptions of the model are summarized in Boxes 2 and 3. The demographic structure of a country is usually considered among the best predictors of pension spending across countries. ${ }^{13}$

\section{Box 1. Methodology}

Two baseline scenarios are presented. In both scenarios the current parametric setup of the pension system is left unchanged. The first baseline scenario calculates the deficit path under the assumption that no improvement in the participation rate of the private and the rural sector takes place. The second baseline scenario derives the level of coverage rate that would generate a financially sustainable system, given current parameterization.

The subsequent scenarios study different combinations of parametric changes to the system. First, a determination is made of the coverage rate that would result in financial sustainability, given a specific combination of parametric changes to the PAYG system of the urban pension fund. Second, a qualitative assessment of the realism of each scenario is provided, e.g., whether the parametric changes in the scenario are likely to result in a coverage rate that would make the system sustainable. The demographic and macroeconomic assumptions remain unchanged in all scenarios.

\section{Baseline scenarios}

The first baseline scenario assumes that the participation level remains constant except for that of the state sector, whose weight is assumed to decrease rapidly on account of privatization and the streamlining of the public sector (Table 3). This scenario results in a financially unsustainable situation with the total deficit of the pension fund growing to over 2 percent of GDP in 2048, more than twice its current level. Specifically, the deficit of the rural scheme doubles, to 0.4 percent of GDP in 2048, while the deficit of the urban scheme increases by about half a percentage point to about 1.6 percent of GDP. Moreover, the share of the urban population of retirement age receiving pensions decreases to about 60 percent, since the number of contributors from the private sector does not grow while the weight of the state sector becomes smaller. Taking into account the fundamentally different nature of the urban and the rural schemes, the subsequent variations of the model consider reform options for the two schemes separately.

\footnotetext{
${ }^{13}$ See also: World Bank: Albania-Beyond the Crisis; A Strategy for Recovery and Growth, Washington, December 1998, p.76.
} 


\section{Box 2. Demographic Analysis}

According to official data from the Albanian Statistical Institute (INSTAT), Albania's population has grown since 1991 from some 3.26 million to about 3.4 million, that is by about 4 percent over almost a decade. This contrasts with a growth of about 22 percent in the previous decade. The two key explanations for the seminal decline in Albania's population growth rates are a significant decline in fertility and in particular emigration into neighboring countries. Fertility per 1,000 Albanians is estimated to have declined from some 23.7 in 1991 to about 17 in the year 1999. This is partly the result of increased uncertainties and turbulences associated with the transition to a market economy and the wider availability of family planning assistance, as well as the extent of emigration (in particular within the younger generation), which has been at a very high level, given the geographical proximity of Albania to Western Europe and the large developmental gap between Albania and its neighbors.

In order to project Albania's population through 2048, the emigration factor needs to be explicitly considered. Since data on emigration are not available, however, an estimate of the extent of emigration since 1991 has been derived by comparing a hypothetical population path without emigration to the actual population. The hypothetical population path is calculated on the basis of assumptions about fertility and mortality rates in the absence of emigration. Fertility rates in the absence of emigration are assumed to have declined continuously from their level of 23.7 per 1000 in 1991 to 19.7 in the year 1999 ; the mortality rate on the other hand is assumed to have remained constant at about 5 deaths per 1000 people per year, which is in line with available statistics. Based on these assumptions, roughly 350,000 Albanians are estimated to have emigrated since 1991. In 2000, about 0.6 percent of the population emigrated. The peak of emigration occurred in 1992 and 1993 , when a total of 230,000 people are assumed to have left Albania.

For the purpose of projecting the population through 2050 , it is assumed that emigration will remain at the level of 0.6 percent of the population in 2000 and that the fertility rate will remain constant at about 18.7 per 1000 , the average of the years 1996-2000. One might argue that fertility rates should increase again as economic prospects improve, but this trend is counteracted by the growing urbanization which tends to depress fertility rates. Mortality rates which are already quite low are expected to remain at this level, as the positive effects of gradual improvements in the quality of health care are offset by the detrimental effects of growing urbanization on life expectancy. Another essential demographic assumption is the extent of rural-urban migration, since the developments in the urban and the rural Albanian pension systems are disparate. Based on the trend toward urbanization since 1991, the model assumes a gradual increase of the urban population from some 49 percent in 2000 to 65 percent in 2048.

Given the decline in fertility, the model shows a gradual rise in the average age of the population, resulting in an increase of the population above working age relative to the overall population to one-quarter of the population by the year 2048 from its current level of about 15 percent.

\section{Box 3. Macroeconomic Assumptions}

Growth: The model assumes real GDP growth rates of 7 percent through 2003, 8 percent from 2004 through 2008 , and 5 percent from 2009 until 2050 . This strong growth performance reflects the positive economic developments in recent years as well as Albania's largely unexploited economic potentials (tourism, manufacturing, mining etc.). The drop from 8 percent to 5 percent from 2008 to 2009 assumes that the rapid post-transition expansion will come to an end at that time. In line with these growth assumptions, the work force increases from 40 percent of the population in 1999 to 44 percent in 2048, as the number of unemployed declines from 38 to 9 percent of the work force. (These figures are estimates by the Social Security Institute and differ from the official statistics of the Albanian Institute of Statistics, which cover only a small part of the economy). This implies an increase in the number of employed from about $1.4 \mathrm{mn}$ in 1999 to $2.2 \mathrm{mn}$ in 2048 .

Inflation: The inflation rate is assumed to be 3 percent per year throughout.

Pensions and wages : Average wages and pensions in the urban scheme are assumed to grow annually by 8 percent, reflecting the strong growth performance of the economy. Wages and pensions are assumed to grow at the same pace to avoid a deterioration in the replacement ratio, which would be a disincentive to broadening the contribution base. In the scenario that models the integration of the rural with the urban self-employed scheme over the next decade, pensions and contributions in the rural scheme are assumed to grow at a rate of $16-25$ percent per year through 2010 . From 2010 onward, pensions in the rural scheme grow at the same rate as those in the urban scheme. 
Albania: Table 3. The Albanian Pension Fund-Baseline Scenario

Question : How will the deficit of the Albanian pension fund develop, if no improvemen in the coverage of the private sector occur, while the contributions of the state sector decline and all other parameters remain unchanged?

$2000 \quad 2010 \quad 2030 \quad 2048$

Assuptions

$\begin{array}{lrrrr}\text { Coverage rate (in percent): } & 34 & 35 & 32 & 32 \\ & & & & \\ \text { Urban registration rates, of which } & 78.7 & 67.5 & 52.3 & 45.2 \\ \quad \text { State sector } & 62.9 & 56.7 & 44.2 & 35.4 \\ \quad \text { Private sector } & 24.3 & 28.3 & 36.5 & 42.3 \\ \quad \text { Other } & 12.8 & 15.0 & 19.3 & 22.3 \\ \text { Rural registration rates } & 71.3 & 71.3 & 67.3 & 72.5 \\ & & & & \\ \text { Overall participation } & 88.7 & 92 & 85.5 & 83.4 \\ \quad \text { State sector } & 96.8 & 98 & 99 & 99 \\ \quad \text { Private sector } & 78.7 & 78.7 & 78.7 & 78.7 \\ \quad \text { Other } & 67.5 & 67.5 & 67.5 & 67.5 \\ \quad \text { Rural } & 35.7 & 35.7 & 35.7 & 35.7\end{array}$

Balance (in percent of GDP):

Urban Scheme

Rural Scheme $\begin{array}{llll}-0.88 & -0.45 & -1.4 & -1.66\end{array}$

$\begin{array}{llll}-0.26 & -0.28 & -0.34 & -0.42\end{array}$ 
The coverage rate of the urban scheme would have to grow to more than 85 percent by the year 2048 from its current level of 40 percent to make the urban scheme sustainable. ${ }^{14}$ Without parametric changes that would increase the incentive to contribute to the system, administrative reforms of the revenue collection system would have to bring about the higher coverage rate. It seems highly unlikely that administrative reforms alone could accomplish the large improvement that is needed. Instead, the result suggests that systemic changes in the setup of the pension fund need to be adopted to secure financial sustainability of the urban pension, including parametric reforms as discussed in greater detail below.

Table 2. Baseline Scenario, Urban Scheme:Increasing the Participation and Registration Rates so as to Attain Financial Sustainability

\begin{tabular}{lrcrr}
\hline & 2000 & 2010 & 2030 & 2048 \\
\hline & & (In percent) & & \\
Coverage rate & 43 & 50 & 65 & 86 \\
Registration rates, of which & 78.7 & 78.8 & 85.2 & 98.1 \\
State sector & 62.9 & 48.6 & 27.1 & 16.3 \\
Private sector & 24.3 & 34.1 & 48.5 & 55.7 \\
Participation & 88.7 & 92.9 & 94.2 & 95.6 \\
State sector & 96.8 & 98.0 & 99.0 & 99.0 \\
Private sector & 78.7 & 90.7 & 96.7 & 98.7 \\
Balance (in percent of GDP) & -0.88 & -0.1 & -0.27 & -0.16 \\
\hline
\end{tabular}

\section{Reform scenarios-Urban scheme}

\section{Parametric reform options for the PAYG system}

The effects of variations in four fundamental parameters of the urban scheme are analyzed: (i) an increase of the contribution ceiling beyond which no more social security contributions are due, (ii) an increase in maximum benefits, (iii) a reduction of contribution rates, and (iv) an increase in retirement age.

An increase of the contribution ceiling would serve two purposes. First, it could substantially boost revenues by obtaining higher contributions from contributors whose salary exceeds the current ceiling, which is likely below the wage levels earned in parts of the private sector. ${ }^{15}$ Second, it would improve the regressive character of the system in which contributors with lower salaries are required to contribute a proportionately greater share of their salary.

\footnotetext{
${ }^{14}$ This scheme is subsequently referred to as the urban baseline scenario, since it does not factor in policy changes.

${ }^{15}$ There are no comprehensive data on wage levels in the private sector. This conclusion is based on extensive anecdotal evidence.
} 
An increase in maximum benefits would complement the rise in the contribution ceiling, as it would help avoid a drop in the coverage rate. A higher contribution ceiling alone would be a disincentive for contributors with higher wages, unless they were able to obtain higher benefits. An increase in maximum benefits would also correct the current skewedness of the benefit structure, where replacement ratios for contributors within the low and middle range of the taxable wage range are substantially better than for those at the high end of the taxable wage range. ${ }^{16}$ Ceteris paribus, an increase in maximum benefits would involve additional costs to the system.

A reduction in the contribution rates from their currently high level would be beneficial since they represent an impediment to higher employment in the formal sector, distort the labor market, and are a disincentive to participation in the pension fund, particularly in the private sector. A reduction in contribution rates would, however, also be associated with additional costs to the system.

Finally, an increase in the retirement age would be beneficial to the pension fund's financial performance. It would also seem justifiable in light of the relatively high longevity reflected in an average period of 17 years during which pensions are received, even though retirement ages in Albania are currently in line with those in other East European countries.

The subsequent scenarios identify for various combinations of these parametric changes the improvement in the coverage rate that would be necessary to achieve a financially sustainable situation of the urban PAYG scheme and assess the likelihood that the identified parametric changes will elicit greater compliance from the private sector. This approach acknowledges that-in particular in the Albanian circumstances-the scope to widen the contribution base will remain limited unless supported by higher voluntary compliance.

\section{Financial impact of reforms}

First reform scenario: Increasing the contribution ceiling

Table 3. Policy Scenario I: Increasing Contribution Ceiling

\begin{tabular}{lrrrr}
\hline & 2000 & 2010 & 2030 & 2048 \\
\hline Required coverage rate (in percent) & 43 & 44 & 45 & 52 \\
Balance (in percent of GDP) & -0.88 & 0.1 & 0.1 & 0.1 \\
\hline
\end{tabular}

With an increase in the contribution ceiling from three to five times the minimum wage, even a rather modest improvement in the coverage rate would result in a financially sustainable urban scheme. The underlying assumption is that the share of contributors earning in excess

\footnotetext{
${ }^{16}$ With the current maximum pension of about Lek 10,000 per month, a contributor who earns an average monthly wage of about Lek 15,000 has a replacement ratio of more than 60 percent, while someone with an income at the end of the taxable range of Lek 23,000 has 00a replacement ratio of only 40 percent.
} 
of the current ceiling will grow from 4 to over 15 percent, which is rather conservative. The parametric change studied in this scenario results, however, in a greater disincentive for the private sector to participate in the pension fund, because the ratio of average pensions to average contribution base decreases significantly-from about 50 percent to 30 percent. $^{17}$ This result emerges because the gap between the maximum benefits paid and the average wage is widening. ${ }^{18}$

Second reform scenario : Increasing contribution ceiling and maximum benefits

Table 4. Policy Scenario II: Increasing Contribution Ceiling and Maximum Benefits

\begin{tabular}{lrrrr}
\hline & 2000 & 2010 & 2030 & 2048 \\
\hline Required coverage rate (in percent) & 43 & 50 & 67 & 94 \\
Av. Pension/Av. Contribution base (in percent) & 51.4 & 51.4 & 51.4 & 51.4 \\
Balance (in percent of GDP) & -0.88 & -0.3 & -0.4 & -0.16 \\
\hline
\end{tabular}

An increase in maximum benefits coupled with an increase in the contribution ceiling would be highly unlikely to result in a sustainable urban scheme. The second policy scenario studies an increase in maximum benefits that would result in a constant ratio of average pensions to average contribution base of about $1: 2$. Concurrently, the contribution ceiling is raised to five times the minimum wage. With these parametric changes, the coverage rate would have to expand to almost 95 percent by the year 2048 to attain financial sustainability. More specifically, the deficit would narrow quite sharply initially, but widen again as the impact of higher benefits became more noticeable.

Third reform scenario : Increasing the contribution ceiling and reducing contribution rates

Table 5. Policy Scenario III: Increasing Contribution Ceiling-Reducing Contribution Rates

\begin{tabular}{lrrrr}
\hline & 2000 & 2010 & 2030 & 2048 \\
\hline Required coverage rate (in percent) & 43 & 50 & 58 & 77 \\
Contribution rates (in percent) & & & & \\
State Sector & 42.5 & 35.0 & 35.0 & 30.0 \\
Private sector & 42.5 & 35.0 & 35.0 & 30.0 \\
Self-employed & 34.5 & 24.0 & 24.0 & 24.0 \\
Balance (in percent of GDP) & -0.88 & -0.48 & -0.01 & -0.01 \\
\hline
\end{tabular}

\footnotetext{
${ }^{17}$ This figure differs from the replacement ratio since the average wage referred to here is the wage based on which contributions are being paid and not the average wage earned in the public sector.

${ }^{18}$ The regressivity of the benefits formula discussed in this section under footnote 16 results in a progressively deteriorating replacement ratio, as following the increase of the contribution ceiling the number of contributors in higher income brackets increases.
} 
Under this scenario, starting in 2001 contribution rates are cut to 35 percent in the state and private sectors and to 24 percent for the self-employed ${ }^{19}$, while the contribution ceiling is raised from three to five times the minimum wage. The resulting deficit path shows that imbalances can be reduced to zero by the year 2030 , if the coverage rate grows gradually and reaches 77 percent by the year 2048 . While this is about 10 percentage points less than under the urban baseline scenario, it is nonetheless ambitious, in particular considering that the benefits formula remains rather unattractive for higher income earners. At the same time, the scheme may continue to be financially viable with a lower and more easily achievable participation rate, if the retirement age is increased simultaneously. The subsequent scenario assumes an increase of the retirement age for men to 65 and for women to 60 years as of the year 2001 as well as a rise in the contribution ceiling and a reduction in contribution rates.

Fourth reform scenario: Increasing the contribution ceiling/Reducing contribution rates and raising the retirement age

Table 6. Policy Scenario IV: Increasing Contribution Ceiling-Reducing Contribution Rates and Raising the Retirement Age

\begin{tabular}{lrrrr}
\hline & 2000 & 2010 & 2030 & 2048 \\
\hline Required coverage rate (in percent) & 43 & 50 & 54 & 68 \\
Balance (in percent of GDP) & -0.88 & -0.13 & -0.3 & -0.22 \\
\hline
\end{tabular}

Combining these three reforms allows a decline in the coverage rate by about 10 percentage points, compared with the previous scenario in which the retirement age remained unchanged. An improvement of the coverage ratio of that magnitude appears achievable, especially considering that through 2030 only an improvement of about 10 percentage points is required. Since in this scenario the benefits formula is not adjusted-implying the negative repercussions discussed above-another iteration of this scenario looks at the impact of raising in parallel the maximum benefits so as to maintain a constant ratio of average pensions to average contribution base. This results ceteris paribus in a deficit in excess of 3 percent of GDP by the year 2048 which would make the system again financially unsustainable.

\section{Conclusions}

The conclusions suggested by this analysis of parametric reform options to the PAYG system in the urban scheme can be summarized as follows:

\footnotetext{
${ }^{19}$ Contribution rates in the state and private sector are reduced further to 30 percent by the year 2040.
} 
- While the baseline scenario does not result in an explosive deficit path, it shows a loss of importance of the state pension fund as an effective institution for social protection reflected in low participation rates and demonstrates that the urban scheme continues to require significant and gradually rising transfers from the budget. This result suggests that the PAYG system in the urban scheme requires significant reforms to obtain a deeper penetration of the private sector and enhance its financial sustainability. The analysis of four different parametric reforms of the urban scheme in an actuarial model suggests that reductions in the contribution rates as well as increases in the contribution ceiling and the retirement age would be conducive to an increase in participation rates and would enhance the financial sustainability of the system under reasonable assumptions about improvements in the coverage rate.

- Nonetheless, the achievement of the higher coverage rate necessary to attain financial sustainability will require significant administrative efforts (which are discussed further below) especially because the incentive to participate in the urban scheme continues to be low under the proposed combination of parametric reforms, given the relatively low replacement ratio for wage earners at the higher end of the taxable wage range. To help mitigate the impact of relatively low benefits for higher wage earners, the creation of private pension funds could be encouraged in the form of second and third pillars (see Section 3).

- How sensitive are these results to modifications of the model? The model is driven largely by demographic and macroeconomic assumptions. Results could change, particularly if the growth rates for pensions are assumed to be different. While lower growth rates of pensions might have a favorable financial impact, this could also reduce incentives to participate and undermine the achievement of the necessary increase in the coverage rate. Moreover, the calibration of the parametric changes could have an impact on the results of the model, e.g., if contribution rates are lowered at a different pace and by other amounts, or if contribution ceilings are raised by more or less than assumed in this paper. Also, the calculation of the impact of raising the contribution ceiling would be sensitive to assumptions about the share of contributors who earn more than the current contribution ceiling. In that sense, the results of the model have more a qualitative than a quantitative character and should not be considered as numerically precise assessments.

\section{Reform scenarios-Rural scheme}

Reforms of the rural scheme require a direction that is different from those of the urban scheme. On the one hand, contribution rates and benefits are currently only a fraction of those of the urban scheme. On the other hand, wage ceilings are not binding in the case of the rural scheme, as the wage level in rural areas is much below that in the urban scheme. At the same time, the lack of financial sustainability of the rural scheme is even more obvious than that of the urban scheme, since per capita benefits paid under the rural scheme exceed by a factor of 9 to 10 the contributions paid by a farmer. 
In line with recent recommendations of the World Bank ${ }^{20}$, the Albanian pension fund intends to embark over the next decade on a gradual equalization of the contribution rates and benefits of the urban self-employed with those of the rural scheme. Under this reform-which has not yet been initiated yet-the current direct transfer of the budget to the rural scheme resulting from the difference between the actual contributions paid by farmers and the hypothetical level of contributions that farmers would pay if they were treated as urban selfemployed would be gradually phased out and eliminated by 2010 . The actuarial model shows that-should the merger of the rural with the urban self-employed scheme be successful-the rural scheme would become sustainable and require a transfer to the budget of on average only $0.1-0.2$ percent of GDP. This conclusion would also be valid, even without any substantial increase in the participation of the rural sector, since the number of beneficiaries would decline correspondingly. ${ }^{21}$ In the latter case the budget would, however, be burdened by additional payments of ndihma ekonomike (economic aid), since farmers who are not entitled to rural pensions are eligible for social assistance.

Table 7. Policy Scenarios for the Rural Scheme

\begin{tabular}{|c|c|c|c|c|}
\hline & 2000 & 2010 & 2030 & 2048 \\
\hline Contribution rates (in percent) & 4.2 & 34.5 & 34.5 & 34.5 \\
\hline Scenario I & & & & \\
\hline $\begin{array}{l}\text { Participation rate } \\
\text { (in percent of registered work force) }\end{array}$ & 36.3 & 36.3 & 36.3 & 36.3 \\
\hline Balance (in percent of GDP) & -0.28 & -0.3 & -0.74 & -0.17 \\
\hline Scenario II & & & & \\
\hline $\begin{array}{l}\text { Participation rate } \\
\text { (in percent of registered work force) } \\
\text { Balance (in percent of GDP) }\end{array}$ & $\begin{array}{r}36.3 \\
-0.28\end{array}$ & $\begin{array}{r}43.3 \\
-0.14\end{array}$ & $\begin{array}{r}59.3 \\
-0.47\end{array}$ & $\begin{array}{r}63.3 \\
-0.01\end{array}$ \\
\hline
\end{tabular}

The success of a possible merger of the rural with the urban self-employed scheme seems to be highly uncertain, however, since it would require an almost nine fold increase in the per capita contribution of the rural population to the pension fund over the next decade which may be difficult to achieve. Nonetheless, it cannot be ruled a priori that such an increase in per capita contributions can be accomplished since at present contributions amount to only US\$6 to US\$8 per year and the financial capacities of the rural population may be more substantial. In light of the uncertainty of the feasibility of such reforms, the Albanian pension fund should also consider the possibility of replacing the rural scheme with a mandatory defined-contributions pillar.

\footnotetext{
20" Albania: Beyond the Crisis-A Strategy for Recovery and Growth", World Bank, December 1998.
}

${ }^{21}$ This conclusion is somewhat analogous to that reached for constant participation rates in the urban scheme, except that the achievement of this result for the rural scheme would require a successful merger with the urban self-employed scheme, implying an explosive growth of per capita contributions. 


\section{Creation of Second and Third Pillars}

Second and third pillars of the pension fund have been created in a number of transition economies, e.g., Bulgaria, Poland and Slovenia. In the case of Bulgaria ${ }^{22}$, a three-step reform process was chosen in which parametric reforms of the PAYG system were complemented by a second pillar that was initially restricted to certain occupational and special category contributors. From 2002 onward, the second pillar is envisaged to become universal. In addition, a regulatory framework was created for the establishment of a third pillar, stipulating the rules for setting up and managing universal or professional pension funds, and formulating investment restrictions, the supervisory framework, the required management structure, and the minimum number of subscribers necessary for operation.

The establishment of second and third pillars needs to factor in explicitly the extent of costs associated with the transition from a single- to a multi-pillar system. These costs result primarily from the loss of revenue to the first pillar as contributors move to the funded pillars ${ }^{23}$-this would be particularly so if, as suggested, the contribution ceiling is raised increasing mandatory contributions to the first pillar-but also from the conversion of accumulated unfunded pension liabilities into explicit debt. In Bulgaria, employers of special category workers are now required to pay 3 extra percentage points to the first pillar to limit the decline in revenues, while excess contributions paid on their behalf have been assigned to individual funded accounts in the second pillar. Additional transitory costs notwithstanding, the move to a multi-pillar system will be advisable, if it is not certain that reforms of the PAYG system will yield a sustainable pension system.

This paper cannot address the complex design issues associated with the possible move from a single to a multi-pillar system in Albania. The analysis of reform options to the PAYG system suggests, however, that for the urban and the rural schemes funded, definedcontributions pillars should be seriously considered. The design of such pillars should, however, be different in the urban and the rural schemes :

As discussed above, parametric reforms of the urban scheme may result in a financially sustainable situation of the urban scheme under reasonable assumptions about improvements in the coverage rate. The deterioration of the replacement ratio implied by the fact that such reforms cannot sustain upward adjustments in maximum benefits suggests, however, that pension funds-run by the state or privately-that focus on the voluntary participation of contributors with higher wages would be a useful supplementary arrangement for the urban scheme. In order to create incentives for participation in the PAYG scheme, the ability to

${ }^{22}$ See also, "Pension and Health Reforms in Bulgaria: Restoring Sustainability", by Balazs Horvath.

${ }^{23}$ See also, "Aging Populations and Public Pension Schemes", IMF Occasional Paper No.147, by Sheetal K. Chand and Albert Jaeger for a discussion of these issues. 
participate in the private pension fund could be made contingent on parallel enrollment in the state pension fund. The provision of supplementary benefits through a pension fund may also provide an avenue to correct for some of the adverse redistributive effects of the benefits formula-which the proposal leaves unchanged-by offering, e.g., some tax reductions on returns earned by the pension fund. While a voluntary third-pillar type of arrangement may be useful for the urban scheme, the creation of a mandatory, funded second pillar would not seem advisable at this juncture for the urban scheme in Albania, unless the suggested parametric reforms of the PAYG-system turn out to be nonfeasible. The creation of a mandatory funded pillar would withdraw contributions from the PAYG-system, which could well threaten its financial sustainability.

In the rural scheme the situation is different, as the two basic reform options discussed above would both involve the termination of the current system. If the necessary increase in per capita contributions necessary to achieve a successful merger with the scheme of the urban self-employed is not feasible, the rural scheme could be replaced by a funded second pillar. This might be arranged by creating an agency that would invest farmers' contributions into (for example) government treasury bills, which are a risk-free investment with reasonably good returns.

\section{Administrative Reforms}

While Sections 2 and 3 discussed options for systemic reforms of the pension fund, these are unlikely to become fully effective unless they are accompanied by administrative measures to combat evasion and increase the number of contributors.

To this end, the SSI-revenue collection administration should be integrated over a number of years with the General Tax Directorate. There are a number of similarities between the collection of taxes and social security contributions which have led many countries (including Hungary, Slovenia, and Latvia) to combine the administration of the collection functions within the main revenue collection agency. The advantages of adopting this approach are generally that (i) the tax department usually has greater expertise and experience in collecting debt; (ii) the tax department normally has greater powers to acquire information about assets, income sources, and creditors of the defaulter; (iii) economies of scale and enhanced revenue effectiveness are possible by combining these functions; and (iv) compliance costs for taxpayers are reduced if they have to deal with only one organization instead of two. In addition, the SSI currently has few incentives to collect revenues, because its deficit is automatically covered by the state budget. This issue would be helped if the tax directorate collected social insurance contributions.

The integration of the two revenue-collecting agencies is an involved process that should require several years and also depend on progress made in modernizing the tax administration. As a first step, the control functions of both revenue administrations could be integrated. In addition, the cooperation between the social security collection forces and the bailiff offices should be strengthened so as to enhance the ability of the administration to combat private sector evasion. 
Moreover, a major Iong-term measure to boost the number of contributors in the SSI will be to permit the payment of contributions to the Albanian pension fund through pension funds in neighboring countries, notably Italy and Greece. Currently, more than one million Albanians work in these countries, many of them illegally. While the legal emigrants generally pay contributions to the respective Italian and Greek pension funds, illegal emigrants do not have that option and, to a very small extent, utilize the possibility to contribute to the pension fund under the voluntary scheme through Albanian embassies and consulates. The SSI's long-term objective is to permit the legal transfer of SSI contributions from Albanians living legally in neighboring countries. ${ }^{24}$ This could have a major impact on revenue, if the conversion of Albanians living without legal status into residents with legal status in their host countries-which has been frequently discussed in bilateral discussions between the Albanian government and neighboring countries' governments-takes place.

In the short term, participation in the voluntary scheme will be the only avenue to integrate Albanians with no legal status in their host countries into the Albanian social insurance system, since this is the only way they can obtain pension rights. A further measure to enhance the usefulness of the voluntary scheme would be to abolish the current requirement of at least one month's previous participation in the SSI under the mandatory scheme, especially since many young Albanians do not meet this requirement, thus blocking further revenue increases from this segment of potential contributors.

\section{ConCLUSIONS}

The results of the actuarial analysis of the PAYG system suggest that the current system is unsustainable and will continue to require large transfers from the budget unless the social contribution base is increased, particularly by greater participation from the private sector.

For the urban scheme, the study concludes that an advisable combination of parametric reforms may consist of a rise in the contribution ceiling combined with a reduction of contribution rates and an increase of the retirement age. To provide greater incentives to private sector participation, private pension funds could be created to target primarily the higher income segments of the population and to offer supplementary old-age pensions; the possibility of participating in such pension funds could be made conditional on simultaneous participation in the state pension fund.

For the rural scheme, the study concludes that if the planned merger of the rural with the urban self-employed scheme does not succeed, the PAYG system should be abolished and replaced by a funded second pillar. In addition, the study emphasizes that extensive administrative reforms will be required in order to achieve a marked improvement in the participation of the private sector and to ensure financial sustainability.

${ }^{24}$ While an agreement with Turkey has already been concluded, negotiations with Greece and Italy are ongoing. 


\section{Non-Pension Related Functions of the Social Insurance Institute}

\section{Non-pension benefits}

The SSI also pays maternity, temporary incapacity, and invalidity benefits as well as workmen's compensation and survivor benefits. Of these, the maternity benefits-which are paid for one year at a rate of about 80 percent of the insured salary for the first and 50 percent for the second six months-are the most important ones from a quantitative point of view. The condition for benefiting from maternity benefits is to have contributed to the SSI during at least one year immediately before giving birth. The extent of usage of maternity benefits is generally below the level implicit in the composition of contributors, as many mothers do not take advantage of the full year, given the rather low benefits.

Temporary incapacity compensation is paid to eligible employees at a rate of 80 percent of the insured salary to workers falling ill $^{25}$ and a rate of 100 percent up to six months to a worker who has been incapacitated due to an accident. In case the incapacitation lasts for more than six months, the worker is eligible for an invalidity payment equivalent to the insured salary.

\section{Supplementary pensions}

In addition to the regular old-age pensions, the SSI also administers special supplementary pensions that are directly funded by the budget. These pensions serve the purpose to provide special incentives to some civil servants. Among the most important programs in this respect are supplementary military pensions, whose total cost is expected to amount to some Lek 940 million (or 3 percent of total SSI expenditures) in the year 2000 and to which every soldier is entitled once he has reached regular retirement age. This supplement amounts currently to almost US $\$ 100$ per month per soldier. In addition, at the age of 47 every soldier-assuming he has completed at least 15 years of service-is entitled to an early retirement package that should not exceed the maximum pension that he will receive at the time of regular retirement.

If a soldier's job has been eliminated before he has been officially released from the armed forces, he is also entitled to a transitory payment that should assist him until his formal discharge from the armed services when he is eligible for official early retirement. The generous package available to soldiers aims at mitigating the effects of the drastic reduction in the size of the armed forces which might be politically sensitive. In addition to military officials, veterans also receive a supplement to their pension which amounted to some 4 percent of total expenditures of the SSI in 1999 and is accorded in line with the number of

\footnotetext{
${ }^{25}$ Seventy percent, if the employed has contributed for fewer than ten years to the system.
} 
years spent in war. The average benefit for a veteran amounts to about US\$100 per year and is hence quite modest compared with benefits enjoyed by other military officials.

Other individuals who receive supplementary pensions are high officials of the state, such as former ministers. These pensions amounted to only some Lek $55 \mathrm{mn}$ in 2000, and hence represented a very small part of total SSI-expenditures, even though the individual level of pension can exceed Lek 16,000 per person per month.

\section{Price compensation benefits}

The most important supplementary benefit paid to all pensioners by the SSI are various forms of compensation payments to offset the social impact of steep increases in the prices of some essential commodities (electricity; heating oil; bread; food) resulting from the liberalization of prices following transition. Currently, price compensation schemes account for some 15 percent of total expenditures. In addition to pensioners, individuals who are taking care of them are also eligible to price compensation payments. The price compensation payments have not been indexed since their inception in 1993. The only change of substance occurred in 1994, when the food subsidy of Lek 494 per person per month was phased out for pensioners and became part of the regular pension. Currently, pensioners receive an electricity subsidy in the amount of Lek 350 per month and a bread and heating oil subsidy in the amount of Lek 150 per month. ${ }^{26}$ In addition, they obtain on behalf of the family member who takes care of them a subsidy of Lek 414 per month, which is prorated in accordance with a dependency coefficient calculated as the ratio of the number of dependents and the number of pensioners. Accordingly, if one dependent takes care of two pensioners, the ratio would be 0.5 , meaning that each pensioner receives Lek 207 per month in additional pension benefits. On average, the dependency ratio is now 0.57 . As a result of these benefits, rural pensions are doubled compared with the level they would be without the price compensation benefits.

The SSI concedes that price compensation benefits are frequently abused, especially in regard to compensation for dependents, who frequently do not live with them in the same apartment, as stipulated by the law. Moreover, they are paid in many cases to individuals who have never paid for electricity. ${ }^{27}$

\section{Unemployment and health insurance}

The SSI also collects contributions on behalf of the unemployment and health insurance program. Contributions to unemployment insurance are included in the general SSI

\footnotetext{
${ }^{26}$ These amounts have remained unchanged since 1993.
}

${ }^{27} \mathrm{~A}$ case in point is Shkodra, where only 12 percent of households paid for electricity in the year 2000 , but more than 50 percent receive compensation payments for electricity. 
contributions of 32.5 percent for the employer and 10 percent for the employee. According to the SSI law, unemployment benefits should be paid at the level of the minimum urban pension, but in 1995 the Council of Ministers decided to reduce this to Lek 2,800 per month. Since 1995, this amount has not been adjusted.

In contrast to the health insurance contributions, the unemployment benefits are retained by the SSI and declared as part of their own revenues, consequently forcing the budget to pay these benefits out of general budgetary resources. While from a budgetary point of view this is a neutral transaction, as in the case of a transfer of unemployment benefits to the budget and the Labor Offices the SSI would have a larger deficit which would have to be covered by the budget. Nonetheless, this presentation results in an understatement of the SSI's deficit with potential implications for the assessment of the soundness of this system. 


\section{REFERENCES}

Sheetal K. Chand and Albert Jaeger, 1996, "Aging Populations and Public Pension Schemes," IMF Occasional Paper No.147 (Washington: International Monetary Fund).

Balazs Horvath, 2000, "Pension and Health Reforms in Bulgaria: Restoring Sustainability,"in "Bulgaria: Selected Issues ", (Washington: International Monetary Fund).

G.A. Mackenzie, Philip Gerson, and Alfredo Cuevas, 1997, "Pension Regimes and Saving," IMF Occasional Paper No.153 (Washington: International Monetary Fund).

World Bank, 1998, Albania: Beyond the Crisis. A Strategy for Recovery and Growth. December.

World Bank, 1996, Albania: Growing Out of Poverty 